\title{
Integrating functional diversity into tropical forest plantation designs to study ecosystem processes
}

\author{
Christopher BARAloto ${ }^{1 *}$, Eric MARCON ${ }^{2}$, François MorneAU $^{2}$, Sandrine PAVOINE $^{3}$, \\ Jean-Christophe RoGGY ${ }^{1}$ \\ ${ }^{1}$ INRA, UMR "Ecologie des Forêts de Guyane", Kourou, French Guiana \\ ${ }^{2}$ AgroParisTech, UMR "Ecologie des Forêts de Guyane", Kourou, French Guiana \\ ${ }^{3}$ UMR "Conservation des espèces, restauration et suivi des populations" Muséum National d'Histoire Naturelle, Paris, France
}

(Received 16 May 2009; accepted 15 September 2009)

Keywords:

complementarity /

ecosystem function /

functional groups /

leaf economics spectrum /

nitrogen fixation /

quadratic entropy

\begin{abstract}
- The elucidation of relationships between biodiversity and ecosystem processes has been limited by the definition of metrics of biodiversity and their integration into experimental design. Functional trait screening can strengthen the performance of these designs.

- We suggest the use of Rao's quadratic entropy to measure both functional diversity and phylogenetic diversity of species mixtures proposed for an experimental design, and demonstrate how they can provide complementary information.

- We also present an index assessing the statistical performance of these independent variables in different experimental designs. Measurement of independent variables as continuous vs. discrete variables reduces statistical performance, but improves the model by quantifying species differences masked by group assignments.

- To illustrate these advances, we present an example from a tropical forest tree community in which we screened 38 species for nine functional traits. The proposed TropiDEP design is based on the relative orthogonality of two multivariate trait axes defined using principal component analysis.

- We propose that independent variables describing functional diversity might be grouped to calculate independent variables describing suites of different traits with potentially different effects on particular ecosystem processes. In other systems these axes may differ from those reported here, yet the methods of analysis integrating functional and phylogenetic diversity into experimental design could be universal.
\end{abstract}

Résumé - Diversité fonctionnelle et processus écosystémiques dans des assemblages synthétiques d'espèces d'arbres de forêt tropicale.

- La compréhension des relations pouvant exister entre biodiversité et fonctionnement des écosystèmes a été longtemps limitée par la définition de méthodes de quantification de la diversité biologique et la mise en œuvre de dispositifs expérimentaux permettant sa mesure. L'identification de syndromes de traits fonctionnels clefs influençant des fonctions écosystémiques particulières peut renforcer la performance de ces dispositifs.

- Nous suggérons l'utilisation de l'entropie quadratique de Rao pour mesurer la diversité fonctionnelle et phylogénétique dans des assemblages synthétiques d'espèces, et montrons comment ces mesures de diversité sont complémentaires.

- Nous présentons également un indice permettant de tester la performance statistique de ces variables indépendantes dans différents modèles expérimentaux. L'utilisation de variables indépendantes continues plutôt que discrètes réduit la performance statistique mais améliore le modèle en quantifiant les différences fonctionnelles entre espèces ; différences généralement masquées lors de leur assignation en groupes fonctionnels.

\footnotetext{
* Corresponding author: Institut National de la Recherche Agronomique, BP 709, 97387 Kourou, France, chris.baraloto@ecofog.gf
} 


\begin{abstract}
- Pour illustrer ces avancées, nous présentons un exemple d'assemblages synthétiques à partir de 38 espèces d'arbres de forêt tropicale sélectionnées pour 9 traits fonctionnels (TropiDEP). Le plan d'expérience de TropiDEP est basé sur l'orthogonalité relative de deux axes multivariés de traits fonctionnels définis par analyse en composantes principales.

- Nous proposons que les variables décrivant la diversité fonctionnelle soient groupées pour calculer des variables indépendantes, divisées en plusieurs axes décrivant des combinaisons de différents traits pouvant influencer des processus différents de l'écosystème (e.g. processus du $\mathrm{N}$ et du C). Dans d'autres systèmes, ces axes peuvent différer de ceux présentés ici, mais les méthodes d'analyse peuvent être universelles.
\end{abstract}

\section{INTRODUCTION}

The rapid and pervasive loss of biodiversity over the past century has provoked debate about the consequences of species loss for ecosystem function and the stability of biogeochemical cycles (e.g., Schwartz et al., 2000). Understanding the relationship between biodiversity and ecosystem processes (B-EP) has thus become one of the critical issues in contemporary ecology (Chapin et al., 2000; Loreau et al., 2001). Although some experiments have found links between biodiversity and ecosystem parameters such as primary productivity or nitrogen retention, other experiments have not found these effects (Hooper et al., 2005). These conflicting results may be due in part to the means by which the B-EP relationship is investigated and analyzed (Diaz and Cabido, 2001; Hooper et al., 2005; Huston et al., 2000; Loreau and Hector, 2001; Wright et al., 2006). Such discussions have moved the central question from whether biodiversity affects ecosystem processes, to what mechanisms underly these relationships and how do they differ between systems (Cardinale et al., 2007; Ewel, 2006; Fargione et al., 2007; Gamfeldt et al., 2008; Hector and Bagchi, 2007; Hillebrand et al., 2008; Hooper and Dukes, 2004; Isbell et al., 2009; Naeem and Wright, 2003; Polley et al., 2007; Reich et al., 2004; Roscher et al., 2004; Zhang and Zhang, 2007).

In this paper, we suggest improvements for studying the biodiversity-ecosystem process relationship (hereafter B-EP) using experiments manipulating species and functional diversity. We focus on forest ecosystems, using a tropical tree community as a model system for several reasons. First, tropical forests are among the most diverse plant communities described and thus offer a large pool of species, including hundreds of nitrogen-fixing legumes that differ widely in functional traits related to carbon and water cycling (Bonal et al., 2000; Roggy et al., 1999). Second, tropical forests play a major role in global biogeochemical cycles; they may account for more than a third of global net primary productivity (e.g., Phillips et al., 1998). Finally, tropical forests are undergoing rapid conversion to deforested areas for livestock, agriculture and mining, and recent attention has focused on how to rehabilitate converted tropical forests (Lamb et al., 2005; Parrotta and Knowles, 1999). Yet, only a handful of experimental plantations manipulating mixtures of forest trees exist, all of which incorporate some limitations for studying B-EP related to the choice and number of species tested and the design of experimental plots (Ewel, 2006; Scherer-Lorenzen et al., 2005).
In particular, we address two general limitations of current B-EP research that are particularly lacking in the experimental approach used in extant forest plantation studies. First, we focus on how bioviversity is defined and measured in designing and evaluating B-EP experiments (Petchey and Gaston 2006; Wright et al. 2006). Second, we examine the statistical performance of different experimental designs and propose a compromise between practical implementation and statistical rigor using a new performance measure. We illustrate our proposed improvements using as a case study TropiDEP, an experimental design based on a matrix of traits and phylogenetic information assembled for French Guianan tree species.

\section{DEFINING AND MEASURING BIODIVERSITY}

It is now well accepted that the general relationships between species number and ecosystem processes such as productivity are the result of functional differences among species. Accordingly, the use of species richness as a proxy for functional diversity has been criticized as too coarse a measure for predicting ecosystem parameters (Petchey et al., 2004; Petchey and Gaston, 2006; Roscher et al., 2004). Still, the best means to estimate functional diversity for both the design and analysis of B-EP experiments remains contentious (Petchey and Gaston, 2006; Ricotta, 2005; Wright et al., 2006). Although analyses can be performed using post-hoc attributions of species to groups or post-hoc measures of diversity, designs generally incorporate some a priori designation to maintain balance and to avoid problems of circularity (Wright et al., 2006).

In general, two approaches have been used to estimate a priori functional diversity in B-EP experiments. Most studies have used a broad designation of species groups based on key traits such as growth form, photosynthetic pathway, or N-fixing capacity (Ewel, 2006; Hooper and Dukes, 2004; Reich et al., 2004; Tilman et al., 2001). Broad designations are often easy to employ because they rely on "soft" traits that are readily distinguished for most species and are easily scored as categorical variables (Hooper et al., 2005). Broad designations also permit the identification of types of species that have particular effects on ecosystem processes or that may complement species from other groups (e.g., Ewel, 2006; Hooper and Dukes, 2004; Reich et al., 2004). However, broad designations mask within-group trait variability, and such fine-scale differences may also be of consequence for ecosystem processes (Craine et al., 2002). 
A fine-scale approach relies on quantitative differences between species in the values of particular functional traits that are hypothesized to affect ecosystem processes (Mason et al., 2003; Ricotta, 2005). For example, Petchey and Gaston (2006) proposed a quantitative measure of functional diversity (FD) analogous to a similar measure of phylogenetic diversity (PD; Faith, 1992) that is based on the branch length of the functional dendrogram of species clustered in trait space. Their index appears to be a better predictor of aboveground productivity than species richness or other measures of functional distance (Petchey et al., 2004).

Biodiversity can be represented not only by species and functional diversity but also by the diversity in evolutionary relationships among taxa (Faith, 1992; Forest et al., 2006). If traits are conserved within lineages, then functional diversity should be tightly correlated with phylogenetic diversity; for example, among vascular plants nitrogen-fixation occurs almost exclusively within legumes (Wojciechowski et al., 2005). However, the extent to which other functional traits are evolutionarily conserved remains under debate. Wood density appears to be highly conserved within higher taxonomic units (Chave et al., 2006), whereas seed mass shows strong divergence within genera (Moles et al., 2005).

A third problem encountered by traditional designs is that even continuous measures of functional diversity such as FD do not account for differences in the relative abundances of species in experimental plots. A recently popularized measure of diversity, the quadratic entropy (Rao, 1982), takes into account both species abundances and pairwise distances among species (Botta-Dukát, 2005; Pavoine et al., 2005). When all species are considered functionally equivalent, the index is equivalent to the Gini-Simpson index (Pavoine et al., 2005). Botta-Dukát (2005) showed that in addition to accounting for abundance and integrating multiple traits, the Rao index satisfies a priori criteria proposed by Mason et al. (2003). The Rao index is thus suitable to contrast diversity in terms of species richness, functional diversity and phylogenetic diversity.

\section{DESIGNING EXPERIMENTS ADDRESSING BIODIVERSITY AND ECOSYSTEM PROCESSES}

The classical statistical model used in the literature to assess the relationship between diversity and ecosystem processes is a linear regression (Loreau and Hector, 2001). By constructing a sample design of multiple plots, one controls the values of a set of variables such as species richness in each plot. These values are contained in a vector $\mathbf{x}$, where $\mathbf{x}^{\prime}=\left(x_{1}, \ldots, x_{j}, \ldots, x_{p}\right)$. After a period of time, a response $y$ is measured in each plot, for example net primary productivity (NPP), and this response is assumed to be given by $y=\mathbf{x} \boldsymbol{\theta}+\boldsymbol{\varepsilon}$, where $\boldsymbol{\theta}$ is the vector of parameters to estimate and $\boldsymbol{\varepsilon}$ is the error vector of variance $\sigma^{2}$. For improved estimates, several $(n)$ plots must be investigated, each of which is submitted to a defined sample design. Together, these plots can be described by a matrix $\mathbf{X}$ whose rows give the $n$ vectors corresponding to the values fixed for the $p$ variables in the $n$ plots and a vector $\mathbf{y}$ of $n$ observed responses. Consequently, the model can be written as a matrix formula as

$$
\mathbf{y}=\mathbf{X} \boldsymbol{\theta}+\boldsymbol{\varepsilon} .
$$

The precision of the estimation of $\boldsymbol{\theta}$ is given by the matrix of variance/covariance $\left(X^{\prime} X\right)^{-1} \sigma^{2}$. One can not control for the model error $\sigma^{2}$, due to the unobserved factors, but the matrix $\left(X^{\prime} X\right)^{-1}$ depends solely on the design. We denote $V_{j k}$ its terms. The variance of the estimator $\hat{\alpha}_{j}$ is $\sigma_{j}^{2}=V_{j j} \sigma^{2}$. The optimal design is characterized by smaller parameter estimation variance and smaller correlations between parameter estimations. By definition, the simplest factorial experimental design, in which only extreme values of the factors are retained and combined in all possible ways, is statistically optimal (Cochran and Cox, 1992).

However, an experimental design must also be able to confirm the assumed linearity of the statistical model. Linearity of ecosystem processes such as NPP has been shown only for species richness (expressed as a logarithm). Tilman et al. (2001) estimate that the relation is probably asymptotic for functional diversity; it would be linear for low diversity only. Intermediate values of the factors that are not included in the basic factorial design are necessary to describe nonlinear relationships. An alternative is a complete design, which includes all possible combinations of factor levels.

Two other considerations are important to experimental design. First, because functional diversity and the number of species are partly correlated, some designs (e.g., high diversity with a single species) are impossible. Second, the effects of particular species may dominate the response of all plots where they are present (Loreau and Hector, 2001). Replication with different species is therefore necessary to avoid biases in estimations. For each level of specific and functional diversity, several plots with alternative species have been proposed (e.g., Roscher et al., 2004). For biodiversity experiments, a potential solution is to replicate the complete design with different species combinations. However, when the species pool is large, as is the case in diverse systems, it becomes impractical to test all possible combinations. Consequently, a strategy for choosing species combinations is necessary.

The different constraints on experimental design are often contradictory, so compromises must be reached. Adding intermediate values of factors (e.g., species number) can help to detect non-linearity, but it also decreases factors' variance and consequently estimation precision. To allow a rational choice, we define a performance measure for experimental designs investigating diversity effects on ecosystem processes.

Assuming normality and denoting $t$ the Student variable, we know the confidence interval for each parameter: $C I\left(\alpha_{j}\right)=$ $\left[\hat{\alpha}_{j}-t \frac{\sigma_{j}}{\sqrt{n}} ; \hat{\alpha}_{j}+t \frac{\sigma_{j}}{\sqrt{n}}\right]$. We rearrange it so that the confidence interval of the estimation of the parameter $\mathrm{j}$ is the product of four independent terms: $\sigma$, the standard deviation of the model's error term; $n$, the number of experimental plots; $S_{j}$, a scale factor reflecting the units chosen; and $P_{j}$, the performance of the design. We can write:

$$
C I\left(\alpha_{j}\right)=\left[\hat{\alpha}_{j}-t \frac{\sigma}{\sqrt{n} S_{j} P_{j}} ; \hat{\alpha}_{j}+t \frac{\sigma}{\sqrt{n} S_{j} P_{j}}\right] .
$$


The number $n$ of plots can be considered as an economic variable. Doubling the design divides the estimators' confidence interval by $\sqrt{2}$. After choosing the minimum (unit) design, repeating it is a matter of finance.

$$
S_{j}=\sqrt{\left(x_{j}^{\max }-x_{j}^{\min }\right)^{2} / 2} \text {, where } x_{j}^{\max } \text { and } x_{j}^{\min } \text { are the ex- }
$$
treme values of $\mathbf{X}_{j}$. It is a scale factor which only ensures the homogeneity of the equation.

$P_{j}=1 /\left(S_{j} \sqrt{V_{j j}}\right)$ is the performance of the design for variable $j^{1}$. It is 1 for the factorial design (the one containing extreme values only), and less than 1 for other designs. It can be easily computed for each potential design to evaluate its relative efficiency. For example, $P_{j}=50 \%$ means that everything else equal, the confidence interval will be doubled, or that twice more plots will be necessary to achieve the same precision in the estimation of the parameter as in the factorial design. This metric thus allows a comparison of the same model with different values of exogenous variables and/or a different number of replications.

The other point of interest is the correlation between parameters $j$ and $k$, given directly by $\frac{V_{j k}}{\sqrt{V_{j j} V_{k k}}}$. Performances for different variables and correlations may vary in opposite directions when the design is changed. Yet, we have the necessary information to evaluate the ratio of performance to infrastructure cost. Practically, the factorial design is taken as a reference since its cost is the lowest; variances are as low as possible (all $P_{j}$ equal 1 by construction), and covariances are null. The real designs, which face other constraints, have higher costs and correlations.

\section{A CASE STUDY EXAMPLE: TROPIDEP}

As a case study, we present TropiDEP, an experimental design for B-EP in a tropical forest ecosystem, that differs in two key ways from other B-EP designs reported to date. It incorporates the multiple axis approach to functional distances, and it can be modified to strengthen its statistical power using discrete or continuous independent variables, based on the statistical performance metrics described above. In this way, it represents a compromise to multiple replications of the complete design.

\subsection{Functional trait measurement}

We measured a series of traits (see Tab. I) for a set of 38 focal species that are common in lowland tropical forests in French Guiana and that represent the most abundant tree families in the Guiana Shield. We made a particular effort to include legume species of the subfamily Mimosoideae that are known to maintain associations with nitrogen fixing Rhizobium symbionts (Roggy et al., 1999).

\footnotetext{
${ }^{1}$ The form of $P_{j}$ is appropriate because in the case of the factorial design, $S_{j}$ is the variance of $\mathbf{X}_{j}$ and $V_{j j}=1 / S_{j}^{2}$. $P_{j}$ is actually a normalized ratio of variances of estimators.
}

Table I. Functional traits measured for a regional species pool of functional diversity. All foliar traits have been standardized to a leaf mass basis, and were measured on juveniles of two years age under controlled conditions in shadehouses.

\begin{tabular}{|c|c|c|}
\hline Attribute (Abbreviation) & Unit & Measurement \\
\hline Foliar $[\mathrm{C}]:[\mathrm{N}]\left(\mathrm{C}_{m}-\mathrm{N}_{m}\right)$ & $\mathrm{g} \mathrm{g}^{-1}$ & $\mathrm{CHN}$ autoanalyzer \\
\hline Foliar $[\mathrm{N}]\left(\mathrm{N}_{m}\right)$ & $\mu \mathrm{g} \mathrm{g}^{-1}$ & $\mathrm{CHN}$ autoanalyzer \\
\hline Foliar delta ${ }^{15} \mathrm{~N}$ & $\mu \mathrm{g} \mu \mathrm{g}^{-1}$ & $\begin{array}{l}\text { Mass spec. analysis } \\
\text { (Roggy et al., 1999) }\end{array}$ \\
\hline $\begin{array}{l}\text { Assimilation Rate } \\
\qquad\left(A_{m}\right)\end{array}$ & $\mu \mathrm{mol} \mathrm{CO} 2 \mathrm{~g}^{-1} \mathrm{~s}^{-1}$ & $\begin{array}{l}\text { CIRAS-1 System at } \\
360 \mathrm{ppm} \mathrm{CO}_{2} \text { and } \\
700 \mu \mathrm{mol} \mathrm{m}{ }^{-2} \mathrm{~s}^{-1} \text { PAR }\end{array}$ \\
\hline $\begin{array}{l}\text { Stomatal conductance } \\
\qquad\left(G_{m}\right)\end{array}$ & $\mathrm{mmol} \mathrm{H}_{2} \mathrm{O} \mathrm{g}^{-1} \mathrm{~s}^{-1}$ & $\begin{array}{l}\text { CIRAS-1 System at } \\
360 \mathrm{ppm} \mathrm{CO}_{2} \text { and } \\
700 \mu \mathrm{mol} \mathrm{m}{ }^{-2} \mathrm{~s}^{-1} \text { PAR }\end{array}$ \\
\hline $\begin{array}{l}\text { Relative Growth } \\
\text { Rate (RGR) }\end{array}$ & $\mathrm{mg} \mathrm{g}^{-1} \mathrm{~d}^{-1}$ & $\begin{array}{l}\text { For a harvest period } \\
\text { from } 24-30 \text { months age }\end{array}$ \\
\hline Root nodules (Nodules) & Presence-absence & On roots at final harvest \\
\hline Root-Shoot Ratio (R-S) & $\mathrm{g} \mathrm{g}^{-1}$ & $\begin{array}{l}\text { root biomass/shoot } \\
\text { biomass at final harvest }\end{array}$ \\
\hline Specific Leaf Area (SLA) & $\mathrm{cm}^{2} \mathrm{~g}^{-1}$ & $\begin{array}{l}\text { leaf area/leaf biomass } \\
\text { for new leaves at final } \\
\text { harvest }\end{array}$ \\
\hline
\end{tabular}

Traits were measured on at least eight juvenile plants per species of two years age $(45-203 \mathrm{~cm}$ tall with basal diameter of 5.4-21.3 mm) grown from seed collected from at least three parent trees. The juvenile stage was chosen for two reasons. First, to control for known environmental effects on functional traits (e.g., Bonal et al., 2000), we chose to measure traits under controlled conditions in a shadehouse, which limited the study to juveniles. Second, saplings represent a size at which individuals begin to interact in plantation settings (Scherer-Lorenzen et al., 2005) and are thus relevant to initial measurements of ecosystem processes, such as nitrogen retention and biomass accumulation. Nevertheless, trait values change with ontogeny especially in trees (e.g., Roggy et al., 1999), and subsequent analyses of experimental designs should update trait measurements in concert with measures of ecosystem processes.

All plants were grown in individual $7 \mathrm{~L}$ pots containing a 2:1 mixture of forest loam and sand soil, placed in a shadehouse in Kourou, French Guiana. Light availability was approximately $20 \%$ of full sun photosynthetically active radiation (about $300 \mu \mathrm{mol} \mathrm{m} \mathrm{m}^{-2} \mathrm{~s}^{-1}$, on a cloudless day, with daily integrated level of about $5 \mathrm{~mol} \mathrm{~m}^{-2} \mathrm{~d}^{-1}$ ). Leaf traits were chosen to represent the primary axis of foliar trait variation described in the literature (Cornelissen et al., 2003; Wright et al., 2004). In addition, we described nitrogen nutrition for each species using two variables. First, we analyzed ${ }^{15} \mathrm{~N}$ isotope concentrations for leaf tissue collected in the absence of any fertilization. The delta ${ }^{15} \mathrm{~N}$ ratio can be used to discriminate between the different $\mathrm{N}$ sources used by the species $\left(\mathrm{NH}_{4}^{+}, \mathrm{NO}_{3}^{-}\right.$and $\mathrm{N}_{2}$ ) (Roggy et al., 1999). Second, we scored 


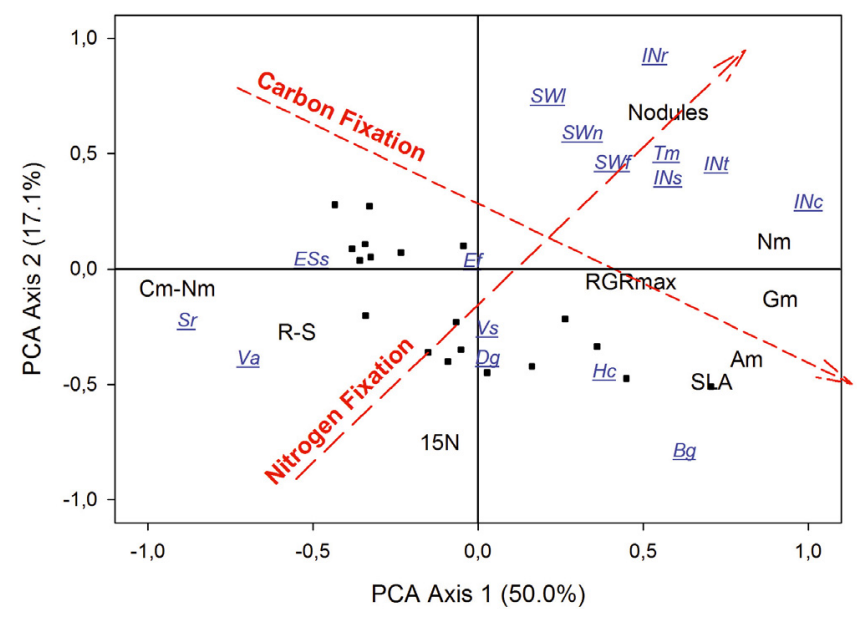

Figure 1. Results of a principal components analysis for correlations among the nine functional traits highlighted in Table I, for the 38 species regional pool in French Guiana. Two axes were defined that explain $67.1 \%$ of variation. Along these factors, four putative functional groups can be defined representing combinations of rates of carbon and nitrogen fixation. Abbreviations for variables are explained in Table I. Species positions in trait space are indicated with squares, except for the 16 focal species focal (four within each functional group), to be manipulated in the proposed TropiDEP experimental design, for which species codes are given (see Tab. II). Note that the nitrogen-fixing legumes do not cover the entire gradient of variation along the carbon diversity axis comprised by the non-fixing species, so for TropiDEP we chose the extreme species with very thick leaves and relatively low photosynthetic capacity within the non-N-fixing slow-growers.

the presence of Rhizobium-containing root nodules on plant with negative values of delta ${ }^{15} \mathrm{~N}$ ratio in order to distinguish $\mathrm{N}_{2}$-fixing legumes from species using $\mathrm{NO}_{3}^{-}$(Schimann et al., 2008); when nodules were present, they were abundant and occurred on all individuals. Table I summarizes the methods and units of measure for the nine traits.

\subsection{Functional trait correlations and focal species selection}

We used a principal component analysis (PCA) to examine correlations among the measured traits, to define interpretable multivariate trait axes, and to project species differences in multivariate trait space. All analyses were conducted in the ade4 module of the $R$ statistical package (Chessel et al., 2004).

The PCA identified two principal axes explaining $67.1 \%$ of trait variation among the 38 study species (Fig. 1). A rotation of the first axis corresponds with what has been described as a global axis of leaf types among plants (Wright et al., 2004), with strong positive loadings of photosynthetic capacity, stomatal conductance for water vapor, and specific leaf area; and strong negative loadings for leaf carbon-nitrogen ratio. A rotation of the second axis segregates $\mathrm{N}$-fixing legumes from other species, with strong positive loading for the nodulation vari- able and a strong negative loading for the ${ }^{15} \mathrm{~N}$ isotope values, confirming this pattern.

We also examined relationships among the species using hierarchical clustering algorithms with Ward's minimum variance method. We calculated Euclidean distances among species pairs derived from three dissimilarity matrices: a phylogenetic matrix based on the angiosperm supertree (Davies et al., 2004); and matrices of traits related to carbon fixation or nitrogen uptake (Tab. I).

From the 38 study species, we chose 16 species representing four broad "functional groups" that combine the carbon and nitrogen axes (Tab. II; projected in Fig. 1) for the TropiDEP design. Within our species pool, the nitrogen-fixing legumes do not cover the entire gradient of variation along the carbon diversity axis comprised by the non-fixing species (Fig. 1). We chose to retain the latter diversity by selecting the extreme species with very thick leaves and relatively low photosynthetic capacity within the non-N-fixing slow-growers. As a result, some species are actually closer in trait space to species assigned to a different group.

The chosen focal species also illustrate how measures of distances between species can be correlated despite the clear separation of trait axes. The strong phylogenetic constraint on $\mathrm{N}$-fixation within legumes results in a slight positive correlation between phylogenetic distance and functional distance along the nitrogen axis. This can be seen in dendrograms of the hierarchical cluster analysis performed on the 16 TropiDEP species (Fig. 2), with the lower cluster in Figure 2c also being clustered in Figure 2a. However, this correlation is weakened because not all legumes in the species pool are $\mathrm{N}$-fixing. A majority of the N-fixing legumes have high foliar nitrogen contents, and tend to grow quickly and have rapid carbon assimilation rates, even if they have thicker leaves. As a result, clusters of species with high values along the carbon axis (Fig. 2b) also tend to be clustered on the nitrogen axis (Fig. 2c). With further trait screening of $\mathrm{N}$-fixing legumes, we might be able to identify species with lower values along the carbon axis to improve the design presented here. However, we can still account for the variability in axis distances for our independent variables by calculating measures of diversity for each experimental plot we create.

\subsection{The TropiDEP design}

The TropiDEP design is based on the relative orthogonality of the two multivariate trait axes defined using principal component analysis (Fig. 1) and their potential effects on particular ecosystem processes (Tab. II). We hypothesize that the consequences of competition and facilitation for ecosystem processes will depend at least in part on independent resourceuse complementarity along each of these axes, such that a global distance measure as proposed by Petchey and Gaston (2002) may mask relationships between functional diversity and ecosystem processes.

To separate these effects, we propose to combine species mixtures that independently include variation along each axis of functional diversity for each level of species richness. This 
Table II. A classification for functional groups of French Guianan trees based on leaf morphology and physiology and nitrogen nutrition status. Also shown are the predicted species properties relevant to ecosystem processes of carbon and nitrogen cycling. The ordination of traits and example species are presented in Figure 1.

\begin{tabular}{|c|c|c|c|c|}
\hline Traits & Light-demandingN-fixers & Light-demanding & Shade-tolerant $\mathrm{N}$-fixers & Shade-tolerant \\
\hline Leaf Structure & High SLA & High SLA & Low SLA & Low SLA \\
\hline Leaf Allocation & High Leaf $\mathrm{N}$ & High Leaf N & High Leaf $\mathrm{N}$ & Low Leaf $\mathrm{N}$ \\
\hline Growth Rate & Fast & Moderate & Moderate & Slow \\
\hline \multicolumn{5}{|l|}{ Processes } \\
\hline Litter Quality & Excellent & Fair & Good & Poor \\
\hline Nitrogen Availability & High & Moderate & Moderate & Low \\
\hline \multirow{3}{*}{ Species } & Inga stipularis (INs) & Dicorynia guianensis (Dg) & Swartzia grandifolia $(S W f)$ & Vоиасароиа атеricana (Va) \\
\hline & Inga thibaudiana (INt) & Hymenaea courbaril $(\mathrm{Hc})$ & Swartzia leblondii $(S W l)$ & Sextonia rubra $(\mathrm{Sr})$ \\
\hline & Tachigali melinonii (Tm) & Virola surinamensis (Vs) & Swartzia panacoco $(S W n)$ & Eperua falcata $(E f)$ \\
\hline
\end{tabular}

a.

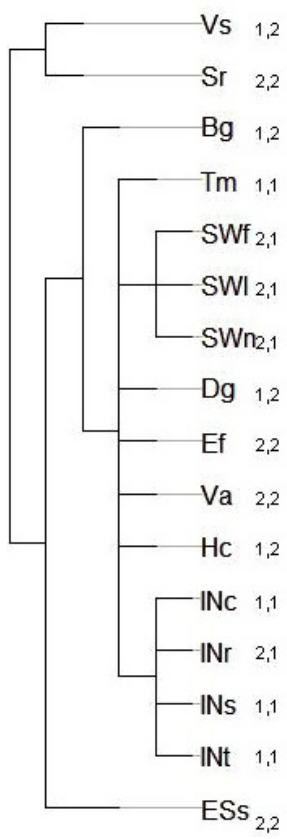

b.

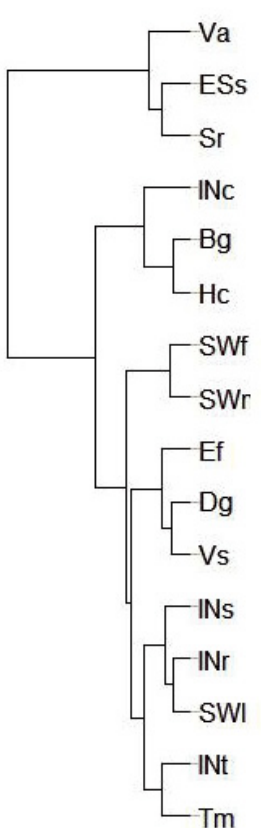

C.

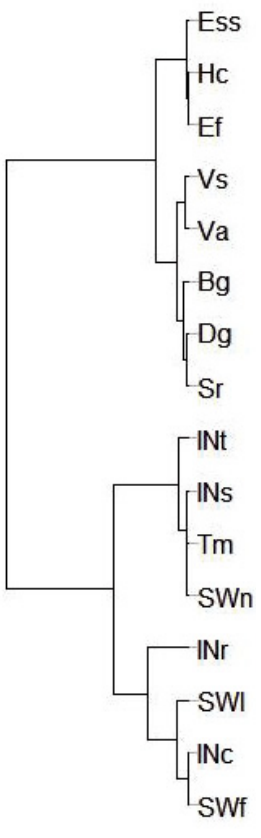

Figure 2. Dendograms for the 16 focal species in the TropiDEP design based on (a) phylogenetic distance, after the angiosperm supertree of Davies et al. (2004); (b) functional trait distance of traits related to carbon fixation and leaf type (see Fig. 1); and (c) functional trait distance related to nitrogen nutrition. Species abbreviations are given in Table II. Subscripts indicate assignments to carbon and nitrogen functional groups, respectively, along the axes presented in Figure 1 and described in Table II.

permits us to study three independent variables - a species variable $(S)$, into which phylogenetic relationships can be integrated; a carbon functional diversity variable $(F D c)$; and a nitrogen functional diversity variable $(F D n)$. The linear model might be written as:

$$
E P=\alpha S+\beta F D c+\gamma F D n+\varepsilon .
$$

To recognize the model of equation (1), this linear model may also be written as

$$
E P=[S|F D c| F D n]\left[\begin{array}{l}
\alpha \\
\beta \\
\gamma
\end{array}\right]+\varepsilon
$$

We used the Rao index of quadratic entropy (Rao, 1982) to calculate the independent variables in the linear model that describe phylogenetic diversity $(S)$ and functional diversity related to carbon fixation $(F D c)$ and nitrogen uptake $(F D n)$. For each plot, the Rao index can be calculated based on a vector of species abundances in the plot, and matrices of species pair dissimilarities calculated for phylogenetic position or functional trait values. We considered the total number of individuals planted in the plots to be 240 based on a planting density of $4 \mathrm{~m}^{-2}$ in a 1 ha plot. In mixed plots, species contributions are equal.

In a classical experimental design, the possible values of factors would be two, four or eight species, and one or two groups of functional diversity (i.e., $F D c$ and $F D n$ may equal 1 or 2). Within this context, a factorial design would include two or eight species, each with one or two groups, treated as discrete categories, for $F D c$ and $F D n$. The complete design would include all combinations of two, four or eight species with one or two discrete groups for each axis of functional diversity, except for the impossible combination of eight species in a single group. A 16-species plot necessarily contains all groups so it is not adapted to either the factorial or the complete design. To account for species identity effects, monoculture plots for each species in the pool must be added (Loreau and Hector, 2001), even though they are not included in the classical designs.

The TropiDEP design is roughly the complete design repeated four times to eliminate species effects and to permit for continuous independent variables (Fig. 3). To avoid replicating identical plots, those with eight species and two groups for $F D c$ (or $F D n$ ) and one group for $F D n$ (or $F D c$ ) are repeated only twice, and a 16-species plot has been added. 


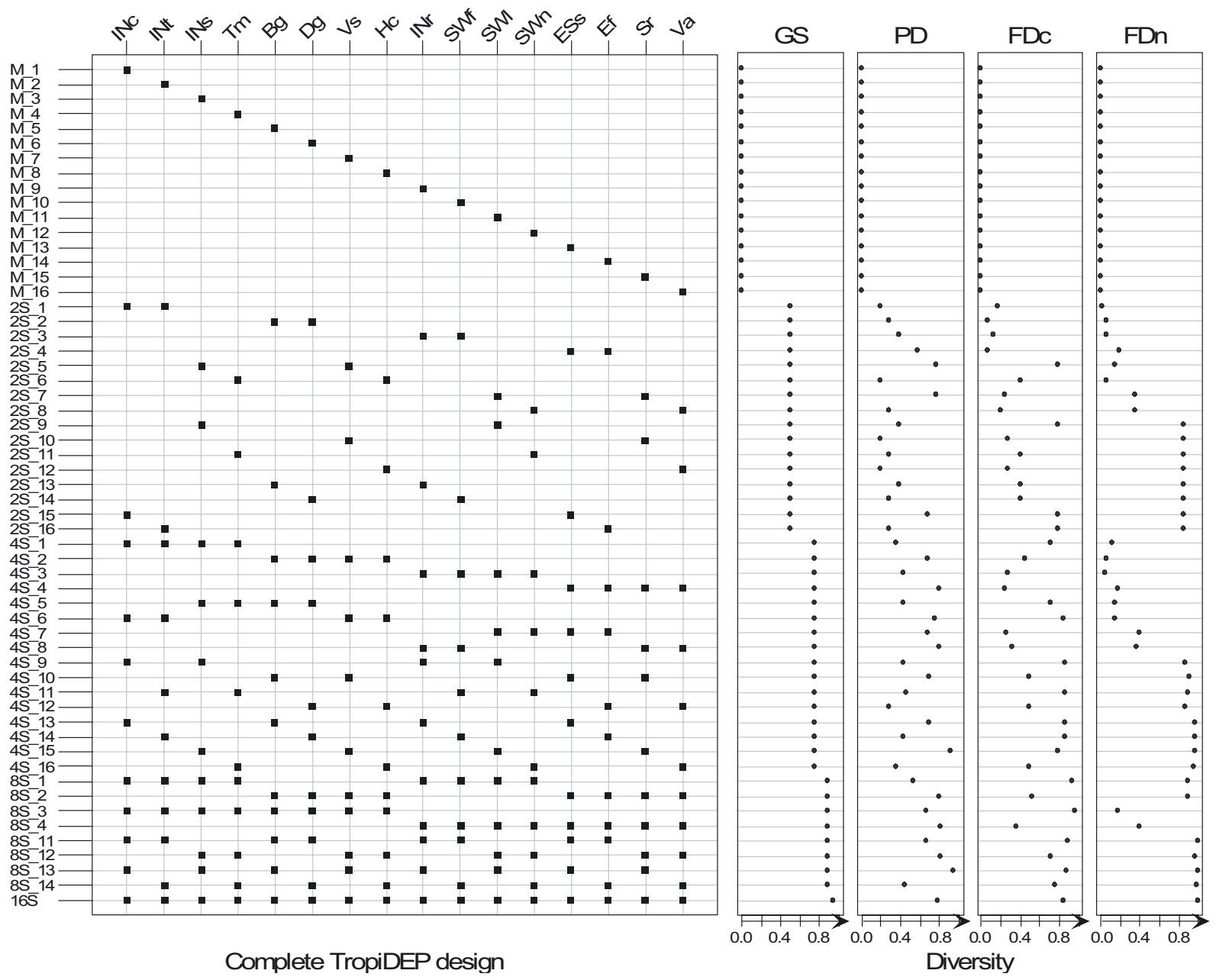

Figure 3. A summary of the 57 proposed plots in the complete TropiDEP design, including the 41 plots in the main design, 16 monocultures and one plot with all 16 species. Shown are the species planted in each plot (with equal relative densities), along with diversity estimates calculated as quadratic entropies with: equal distances among species (Gini-Simpson; GS), phylogenetic distances (PD), and functional distances along trait axes related to carbon $(F D c)$ and nitrogen $(F D n)$ cycling. Species abbreviations are given in Table II. All species are planted with the same number of repititions within richness levels and overall.

\subsection{Comparative performance of TropiDEP and other experimental designs}

Table III presents a summary of statistical performance measures for different experimental designs. We evaluated the TropiDEP design with continuous values as they have been defined in the paper. Its performance estimates using our index are much lower than when these variables are estimated as discrete categories because their variance is reduced. Yet, it is highly probable that the model will fit better with continuous values, so its error $\sigma^{2}$ will be reduced. The actual effect on the variance of the parameter estimators cannot be evaluated before actual experimentation. Nevertheless, we chose this approach because it may permit the identification of diversity effects masked by group designation (cf. Wright et al., 2006).

The first three designs use discrete values including the logarithm of the number of species for species diversity, and the number of functional groups (1 or 2$)$ for functional diversities $F D c$ and $F D n$, so they can be compared directly (Tab. III). For example, suppose we have resources for planting about 80 plots. We can choose to repeat the factorial design 10 times (80 plots), the complete design 7 times (84 plots) or the TropiDEP design twice ( 82 plots). The variance of the PD estimator will be $25 \%(1 / .78 * 80 / 82)$ greater in the TropiDEP design, compared to the factorial design. The PD estimator will also be slightly correlated to the other estimators. This can be considered as the price to be able to verify linearity. Other estimators will be almost as accurate. As such, the performance of TropiDEP is similar to that of the complete design.

The limit of our performance index is that it can not be used to compare completely different models, as we do not know anything about the model error. But it is very useful to evaluate the effect of adding or deleting plots and thus allows fine tuning of a design. For example, we might consider eliminating all of the 4 -species and 16-species plots to simplify the 
Table III. A comparison of statistical performances for experimental designs with sixteen species representing four functional groups along two axes of functional diversity. The factorial, complete and TropiDEP design (with categorical or continuous independent variables) are compared. Performances are relative to the reference factorial design. Corr(V1, V2) is the correlation between the estimators of the effects of variables 1 and 2. The complete design excludes the impossible combination of eight species in a single functional group. The TropiDEP design with continuous variables is based on calculations of quadratic entropies for each plot rather than discrete assignments of presence-absence of a functional group, or number of species.

\begin{tabular}{lcccc}
\hline & Factorial design & Complete design & TropiDEP design, discrete values & TropiDEP design, continuous values \\
\hline $\mathrm{PD}^{a}$ Performance & 1 & $89 \%$ & $78 \%$ & $36 \%$ \\
$F D c^{b}$ Performance & 1 & $95 \%$ & $97 \%$ & $44 \%$ \\
$F D n^{b}$ Performance & 1 & $95 \%$ & $97 \%$ & $67 \%$ \\
Corr(PD, FDc) & 0 & -0.27 & -0.21 & -0.44 \\
Corr(PD, FDn) & 0 & -0.27 & -0.21 & -0.37 \\
Corr $(F D c, F D n)$ & 0 & 0.10 & 0.03 & -0.01 \\
$\mathrm{~N}($ plot number $)$ & 8 & 12 & 41 & 41 \\
\hline Advantages & Most efficient & Can verify linearity & Considers continuous factors \\
Disadvantages & Does not verify linearity & Less efficient & \\
\hline
\end{tabular}

${ }^{a}$ Equivalent to $\log _{2}$ (species number) in discrete analyses.

${ }^{b}$ Equivalent to the number of groups (1 or 2) in discrete analyses.

TropiDEP design more towards a factorial design. The result (not shown in Tab. III) is a negligible performance improvement ( $1 \%$ for all factors), but a higher correlation between $F D c$ and FDn (0.11 instead of -0.01). This 28-plot design could be repeated three times ( 84 plots) to be compared to the TropiDEP design repeated twice (82 plots). Estimation accuracy is not improved and linearity against the number of species can not be verified, so that design would not be retained.

\section{DISCUSSION}

\subsection{The novelty of TropiDEP}

The TropiDEP design incorporates three levels of analysis not examined to date in other studies. First, it incorporates separate functional trait axes that are predicted to influence ecosystem processes in different ways. Although each of the functional trait axes we observed is consistent with trait associations found in this and other plant communities (Roggy et al., 1999; Wright et al., 2004), the relative orthogonality of the two axes has not been reported to date. Together these two axes distinguish species that differ markedly in a suite of traits that could influence carbon and nitrogen cycling in this system (Tab. II). We suggest that distances along each of these axes would provide more interpretable results of the effects of functional diversity than the global distance measure suggested by Petchey and colleagues (Petchey and Gaston, 2002). As a result, we propose that independent variables describing functional diversity might be divided into several axes describing suites of different traits with potentially different effects on particular ecosystem processes. In other sites or ecosystems, these axes may differ from those reported here, yet the methods of analysis could be universal. The definition of separate axes of functional diversity also can improve the choice of focal species for experimental design, such that functional dis- tances among species combinations (cf. Roscher et al., 2004) are varied deliberately along one or more axes.

A second contribution of the TropiDEP design is its consideration of phylogenetic diversity. Biodiversity can be represented not only by species and functional diversity but also by the diversity in evolutionary relationships among taxa (Faith, 1992; Forest et al., 2006). Mixtures of closely related species would then be considered less diverse than those with more distantly related species. Inclusion of this level of analysis might depend on the experimental system and the degree to which the researchers have confidence in their a priori knowledge of functional traits and the phylogenetic constraints on these traits. For example, in our species pool not all legumes fixed nitrogen, but legumes may share other traits we did not measure, such as anti-herbivore defense compounds (Wojciechowski et al., 2005). In this case, we may wish to account for correlations of unmeasured but evolutionarily constrained traits that might influence ecosystem processes, by considering the phylogenetic distance among species pairs in our sample.

We have also shown that both a multivariate measure of functional diversity and a measure of phylogenetic diversity that account for species abundances in experimental plots can be estimated using the Rao quadratic entropy. The Rao index is particularly suited to experimental designs in forest plantations where costs prohibit varying abundances experimentally (e.g., Roscher et al., 2004), and where abundances may vary through time due to self-thinning (Scherer-Lorenzen et al., 2005).

\subsection{Suggestions for experimental designs}

A major limitation to B-EP studies in forest ecosystem involves a trade-off between statistical rigor and feasibility of 
implementation, due to the larger scale and substantial infrastructure required in tree plantations. Several general lessons can be drawn from the construction of the TropiDEP model that should advance the general field of study of functional diversity and ecosystem processes. First, regarding the definition of independent variables using a priori trait measures, researchers may want to account for particular functional traits, the results of which can be easily interpreted (Craine et al., 2002). We suggest screening traits for all potential species, from which one or multiple axes of trait variation can be defined and along which focal species can be chosen.

Second, regarding the measurement of independent variables, we suggest the relationship between diversity and ecosystem processes can only be improved by more precise measurement of the independent variables defining diversity (Wright et al., 2006). In particular, we believe that these variables can often be separated (as in our example for $F D c$ and $F D n$ ). Moreover, the community composition of plots can be measured such that replicates for discrete variables are assigned unique calculated values for independent variables. In addition, measures such as Rao's quadratic entropy (Rao, 1982) can be employed to account not only for continuous distances among species in mixtures but also their relative abundances in each experimental unit.

A third lesson is perhaps obvious but often ignored, and is based on the wide acceptance that complete designs for a linear model are most appropriate (Gotelli and Graves, 1996). We recommend that statistical rigor should be evaluated prior to design implementation. In particular, designs should incorporate not only monoculture plots but also intermediate levels of both species-level diversity and functional diversity along the chosen axes. We propose the use of a performance measure such as that described here to compare among potential designs with particular focal species combinations and relative abundances, to evaluate completely the tradeoffs of particular designs and to choose the experimental design that best meets the objectives of a particular site and project.

Acknowledgements: This work was conducted with funding to CB from NSF OISE 03-01937. We thank Claude Millier and S. Hattenschwiller for productive discussions during the development of this project, and J. Ewel, D. Hibbs, S. Naeem, and F. Putz for constructive comments on the manuscript.

\section{REFERENCES}

Bonal D., Sabatier D., Montpied P., Tremeaux D., and Guehl J.M., 2000. Interspecific variability of $\delta^{13} \mathrm{C}$ among canopy trees in rainforests of French Guiana: Functional groups and canopy integration. Oecologia 124: 454-468.

Botta-Dukát Z., 2005. Rao's quadratic entropy as a measure of functional diversity based on multiple traits. J. Veg. Sci. 16: 533-540.

Cardinale B.J., Wrigh J.P., Cadotte M.W., Carroll I.T., Hector A., Srivastava D.S. et al., 2007. Impacts of plant diversity on biomass production increase through time because of species complementarity. Proc. Natl. Acad. Sci., USA, 104: 18123-18128.

Chapin F.S., Zavaleta E.S., Eviner V.T, Naylor R.L., Vitousek P.M., Reynolds H.L., Hooper D.U., Lavorel S., Sala O.E., Hobbie S.E.,
Mack M.C., and Diaz S., 2000. Consequences of changing biodiversity. Nature 405: 234-242.

Chave J., Muller-Landau H.C., Baker T.R., Easdale T.A., Ter Steege, H., and Webb C.O., 2006. Regional and phylogenetic variation of wood density across 2456 neotropical tree species. Ecol. Appl. 16: 23562367.

Chessel D., Dufour, A.B., and Thioulouse, J., 2004. The ade4 package-IOne-table methods. R News. 4: 5-10.

Cochran W.G. and Cox G.M., 1992. Experimental Designs, John Wiley and Sons, New York, $428 \mathrm{p}$.

Cornelissen J.H.C., Lavorel S., Garnier E., Diaz S., Buchmann N., Gurvich D.E., Reich P.B., ter Steege H., Morgan H.D., van der Heijden M.G.A., Pausas J.G., and Poorter H., 2003. A handbook of protocols for standardised and easy measurement of plant functional traits worldwide. Aust. J. Bot. 51: 335-380.

Craine J.M., Tilman D., Wedin D., Reich P., Tjolker M., and Knops J., 2002. Functional traits, productivity and effects on nitrogen cycling of 33 grassland species. Funct. Ecol. 16: 563-574.

Davies T.J., Barraclough T.G., Chase M.W., Soltis P.S., Soltis D.E., and Savolainen V., 2004. Darwin's abominable mystery: Insights from a supertree of the angiosperms. Proc. Natl. Acad. Sci. USA 101: 19041909.

Diaz S. and Cabido M., 2001. Vive la difference: plant functional diversity matters to ecosystem processes. Trends Ecol. Evol. 16: 646-655.

Ewel J.J., 2006. Species and rotation frequency influence soil nitrogen in simplified tropical plant communities. Ecol. Appl. 16: 490-502.

Faith D.P., 1992. Conservation evaluation and phylogenetic diversity. Biol. Conserv. 61: 1-10.

Fargione J., Tilman D., Dybzinski R., Lambers J.H.R., Clark C., Harpole W.S. et al., 2007. From selection to complementarity: shifts in the causes of biodiversity-productivity relationships in a long-term biodiversity experiment. Proc. Roy. Soc. B. 274: 871-876.

Forest F., Grenyer R., Rouget M. et al., 2006. Preserving the evolutionary potential of floras in biodiversity hotspots. Nature 445: 757-760.

Gamfeldt L., Hillebrand H., and Jonsson P.R., 2008. Multiple functions increase the importance of biodiversity for overall ecosystem functioning. Ecology 89: 1223-1231.

Gotelli N.J. and Graves G.R., 1996. Null Models in Ecology. Smithsonian Institution Press, Washington, 368 p.

Grime J.P., Thompson K., Hunt R., Hodgson J.G., Cornelissen J.H.C., Rorison I.H. et al., 1997. Integrated screening validates primary axes of specialization in plants. Oikos 79: 259-281.

Hector A. and Bagchi R., 2007. Biodiversity and ecosystem multifunctionality. Nature 448: 188-190.

Hillebrand H., Bennett D.M., and Cadotte M.W., 2008. Consequences of dominance: a review of evenness effects on local and regional ecosystem processes. Ecology 89: 1510-1520.

Hooper D.U. and Dukes J.S., 2004. Overyielding among plant functional groups in a long-term experiment. Ecol. Lett. 7: 95-105.

Hooper D.U., Chapin F.S., Ewel J.J., Hector A., Inchausti P., Lavorel S., Lawton J.H., Lodge D.M., Loreau M., Naeem S., Schmid B., Setala H., Symstad A.J., Vandermeer J., and Wardle D.A., 2005. Effects of biodiversity on ecosystem functioning: a consensus of current knowledge and needs for future research. Ecol. Monogr. 75: 3-36.

Huston M.A., Aarssen L.W., Austin M.P., Cade B.S., Fridley J.D., Garnier E., Grime J.P., Hodgson J., Lauenroth W.K., Thompson K., Vandermeer J.H., and Wardle D.A., 2000. No consistent effect of plant diversity on productivity. Science 289: 1255.

Isbell F.I., Polley H.W., and Wilsey, B.J., 2009. Biodiversity, productivity and the temporal stability of productivity: patterns and processes. Ecol. Lett. doi: 10.1111/j.1461-0248.2009.01299.x.

Lamb D., Erskine P.D., and Parotta J., 2005. Restoration of degraded tropical forest landscapes. Science 310: 1628-1632. 
Loreau M. and Hector A., 2001. Partitioning selection and complementarity in biodiversity experiments. Nature 412: 72-76.

Loreau M., Naeem S., Inchausti P., Bengtsson J., Grime J.P., Hector A. et al., 2001. Biodiversity and ecosystem functioning: current knowledge and future challenges. Science 294: 804-808.

Mason N.W.H., MacGillivray K., Steel J.B., and Wilson J.B., 2003. An index of functional diversity. J. Veg. Sci. 14: 571-578.

Moles A.T., Ackerly D.D., Webb C.O., Tweddle J.C., Dickie J.B., and Westoby M., 2005. A brief history of seed size. Science 307: 576580

Naeem S. and Wright J.P., 2003. Disentangling biodiversity effects on ecosystem functioning: deriving solutions to a seemingly insurmountable problem. Ecol. Lett. 6: 567-579.

Parotta J.A. and Knowles O.H., 1999. Restoration of tropical moist forest on bauxite-mined lands in the Brazilian Amazon. Restor. Ecol. 7: $103-116$.

Pavoine S., Ollier S., and Dufour A.-B., 2005. Is the originality of a species measurable? Ecol. Lett. 8: 579-586.

Petchey O.L. and Gaston K.J., 2006. Functional diversity: back to basics and looking forward. Ecol. Lett. 9: 741-758.

Petchey O.L., Hector A., and Gaston K.J., 2004. How do different measures of functional diversity perform? Ecology 85: 847-857.

Phillips O.L., Malhi Y., Higuchi N., Laurance W.F., Núñez P.V., Vásquez R.M., Laurance S.G., Ferreira L.V., Stern M., Brown S., and Grace J., 1998. Changes in the carbon balance of tropical forests: evidence from long-term plots. Science 282: 439-442.

Polley H.W., Wilsey B.J., and Derner J.D., 2007. Dominant species constrain effects of species diversity on temporal variability in biomass production of tallgrass prairie. Oikos 116: 2044-2052.

Rao C.R., 1982. Diversity and dissimilarity coefficients: a unified approach. Theor. Popul. Biol. 21: 24-43.

Reich P., Tilman D., Naeem S., Ellsworth D., Knops J., Craine J. et al., 2004. Species and functional group diversity independently influence biomass accumulation and its response to $\mathrm{CO} 2$ and N. Proc. Natl. Acad. Sci. USA 101: 10101-10106.

Ricotta C., 2005. A note on functional diversity measures. Basic Appl. Ecol. 6: 479-486.
Roggy J.C., Prévost M.F., Gourbière F., Casabianca H., and Garbaye J., 1999. Leaf natural ${ }^{15} \mathrm{~N}$ abundance and total $\mathrm{N}$ concentration as potential indicators of plant $\mathrm{N}$ nutrition in legumes and pioneer species in a rain forest of French Guiana. Oecologia 120: 171-182.

Roscher C., Schumacher J., Baade J., Wilcke W., Gleixner G., Weisser W.W. et al., 2004. The role of biodiversity for element cycling and trophic interactions: an experimental approach in a grassland community. Basic Appl. Ecol. 5: 107-121.

Scherer-Lorenzen M., Potvin C., Koricheva J., Schmid B., Hecto, A., Bornik Z., Reynolds G., and Schulze E.-D., 2005. The design of experimental tree plantations for functional biodiversity research. In: Scherer-Lorenzen M., Korner C, and Schulze E.-D. (Eds.), Forest Diversity and Function: Temperate and Boreal Systems, SpringerVerlag, Berlin, pp. 347-376.

Schimann H., Ponton S., Hattenschwiler S., Ferry B., Lensi R., Domenach A.M., and Roggy J.C., 2008. Differing nitrogen use strategies of two tropical rainforest late successional tree species in French Guiana: Evidence from ${ }^{15} \mathrm{~N}$ natural abundance and microbial activities. Soil Biol. Biochem. 40: 487-494.

Schwartz M.W., Brigha, C.A., Hoeksema J.D., Lyons K.G., Mills M.H., and van Mantgem P.J., 2000. Linking biodiversity to ecosystem function: implications for conservation ecology. Oecologia 122: 297-305.

Simpson E.H., 1949. Measurement of diversity. Nature 163: 688.

Tilman D., Reich P.B., Knops J., Wedin D., Mielke T., and Lehman C., 2001. Diversity and productivity in a long-term grassland experiment. Science 294: 843-845.

Wojciechowski M.F., Lavin M., and Sanderson M.J., 2005. A phylogeny of legumes (Leguminosae) based on analysis of the plastid matK gene resolves many well-supported subclades within the family. Am. J. Bot. 91: 1846-1862.

Wright I.J., Reich P.B., Westoby M., Ackerly D.D., Baruch Z., Bongers F. et al., 2004. The worldwide leaf economics spectrum. Nature 428: 821-827.

Wright J.P., Naeem S., Hector A., Lehma, C., Reich P.B., Schmid B., and Tilman D., 2006. Conventional functional classification schemes underestimate the relationship with ecosystem functioning. Ecol. Lett. 9: $111-120$.

Zhang Q.G. and Zhang D.Y., 2007. Colonization sequence influences selection and complementarity effects on biomass production in experimental algal microcosms. Oikos 116: 1748-1758. 